\title{
Preparation and biodegradable properties of hydroxyapatite nanoparticle composite coated with poly lactic-co-glycolic acid/polyvinyl alcohol for bone regeneration
}

\author{
Feni Istikharoh ${ }^{1,2, A-D}$, Hidayat Sujuti ${ }^{3, E, F}$, Edi Mustamsif ${ }^{A, E, F}$, Astika Swastirani ${ }^{5, B, D}$ \\ ${ }^{1}$ Master Program in Biomedical Science, Faculty of Medicine, Brawijaya University, Malang, Indonesia \\ 2 Department of Dental Materials, Faculty of Dentistry, Brawijaya University, Malang, Indonesia \\ ${ }^{3}$ Department of Biochemistry, Faculty of Medicine, Brawijaya University, Malang, Indonesia \\ ${ }^{4}$ Department of Orthopedics, Faculty of Medicine, Brawijaya University, Malang, Indonesia \\ ${ }^{5}$ Department of Oral Medicine, Faculty of Dentistry, Brawijaya University, Malang, Indonesia \\ A - research concept and design; $\mathrm{B}$ - collection and/or assembly of data; $\mathrm{C}$ - data analysis and interpretation; \\ $D$ - writing the article; $E$ - critical revision of the article; $F$ - final approval of the article
}

Address for correspondence

Feni Istikharoh

E-mail: feni.istikharoh@ub.ac.id

Funding sources

LPPM PNBP 2019 from Brawijaya University, Malang, Indonesia (No. DIPA-042.01.2.400919/2019).

Conflict of interest

None declared

Received on August 28, 2019

Reviewed on June 15, 2020

Accepted on July 27, 2020

Published online on December 31, 2020

Cite as

Istikharoh F, Sujuti H, Mustamsir E, Swastirani A. Preparation and biodegradable properties of hydroxyapatite nanoparticle composite coated with poly lactic-co-glycolic acid/polyvinyl alcohol for bone regeneration. Dent Med Probl. 2020;57(4):363-367. doi:10.17219/dmp/125775

DOI

$10.17219 / \mathrm{dmp} / 125775$

Copyright

○) 2020 by Wroclaw Medical University

This is an article distributed under the terms of the

Creative Commons Attribution 3.0 Unported License (CC BY 3.0)

(https://creativecommons.org/licenses/by/3.0/).

\section{Abstract}

Background. Bone loss rapidly increases 6 months post tooth extraction, which causes the atrophy of the alveolar bone. Two kinds of biomaterials which can stimulate bone regeneration are bioceramics and polymers. Making a composite of biomaterials results in better physical and biomolecular characteristics in comparison with a bioceramic or a polymer alone. Hydroxyapatite nanoparticles (HANPS) are one of the bioceramics commonly used for bone regeneration; they can degrade faster than hydroxyapatite (HA) microparticles, but have an insufficient pore size. Polyvinyl alcohol (PVA) and poly lactic-co-glycolic acid (PLGA) are polymers which have been used for biomedical applications. However, PLGA alone has insufficient cell attachment and PVA alone slowly degrades in the bone tissue.

Objectives. The aim of the present study was to analyze the biodegradation properties of the HANP/PLGA/PVA composites and investigate the pore size.

Material and methods. The HANP/PLGA/PVA composites were prepared using the freeze-drying method, with 20\% (w/w) of HANP and 20\% (w/w) of PLGA. Morphology and the pore size were determined by means of the field emission scanning electron microscopy (FE-SEM) analysis. Biodegradation properties were determined by calculating water uptake and water loss for 1, 3 and 6 weeks. Statistical analysis was performed based on the one-way analysis of variance (ANOVA) at $p<0.05$.

Results. The HANP/PLGA/PVA composites had the greatest mean pore size and a rougher surface than others $(176.00 \pm 61.93 \mu \mathrm{m} ; p<0.05)$. Moreover, the HANP/PLGA/PVA composites had the greatest water uptake, significantly in the $3^{\text {rd }}(730.46 \% ; p<0.05)$ and $6^{\text {th }}$ weeks $(731.07 \% ; p<0.05)$, and water loss in the $6^{\text {th }}$ week $(67.69 \% ; p<0.05)$.

Conclusions. The HANP/PLGA/PVA composites have optimal pore size, morphology and degradability, which shows their high potential as an effective bone scaffold to repair the alveolar defect post tooth extraction.

Key words: biodegradable, bone regeneration, hydroxyapatite nanoparticle, polyvinyl alcohol, poly lactic-co-glycolic acid 


\section{Introduction}

Tooth extraction is one of the most common kinds of dental treatment in developing countries. ${ }^{1,2}$ A total of 944 tooth extraction procedures were performed in 450 patients throughout the year 2014 at Jember Dental Hospital, Indonesia, indicating that each patient was subjected to tooth extraction treatment at least twice a year, on average. ${ }^{3}$ Tooth extraction may negatively impact the alveolar bone, which can result in the atrophy of the alveolar bone, the collapse of the soft tissue, and a short and narrow alveolar ridge. ${ }^{4-7}$ The alveolar bone obviously will lose its function and rapidly disappear in the first 6 months post-extraction. ${ }^{4}$ Other consequences of bone loss include the reduction of esthetics, the inhibition of mastication processes, and the insufficient support of dental implants or prosthetic restorations. ${ }^{4-8}$ Accordingly, it is important to develop biomaterials which could stimulate bone regeneration and prevent bone loss, or for alveolar preservation.

Bone is an inorganic-organic composite material consisting of hydroxyapatite (HA) as the main component. ${ }^{9,10}$ In Indonesia, the most widely used bone grafting material to avoid bone loss following tooth extraction is HA. ${ }^{11}$ However, HA slowly degrades, over approx. 24 months. ${ }^{10-13}$ It is a brittle material, and thus its application is limited to lowpressure areas. Hydroxyapatite nanoparticles (HANPs) are one of the bioceramics that have better osteoconductivity, biocompatibility and biodegradability, and also exhibit enhanced osteoblast adhesion as compared to those of conventional HA. ${ }^{10-12,14}$ This bioceramic may also be able to increase the tensile strength of the scaffold. ${ }^{10}$ However, HANPs have insufficient porosity and pore size. ${ }^{10,14}$ The ideal range of the pore size to promote bone regeneration is $50-300 \mu \mathrm{m} .{ }^{15-17}$ Accordingly, composites constituted by a combination of HANPs and other materials are needed to overcome the limitations of conventional HA. ${ }^{14}$

Polyvinyl alcohol (PVA) and poly lactic-co-glycolic acid (PLGA) are synthetic polymers which possess good stability for bone repair and regeneration. ${ }^{10,18}$ Polyvinyl alcohol exhibits highly favorable properties, such as biocompatibility, and physicochemical characteristics, and has been used for biomedical applications. ${ }^{19,20}$ It has shown better mechanical stability than other polymers, as demonstrated in previous studies. However, the degradation of PVA is very slow. ${ }^{10,19}$ Poly lactic-co-glycolic acid is one of the best biodegradable materials, which is also used as a drug carrier. It degrades into non-toxic products. ${ }^{21-23}$ Nevertheless, neither PVA nor PLGA support cell adhesion. They also have low mechanical support. ${ }^{10,19}$ One study showed that the addition of HA to a polymer scaffold resulted in enhanced osteoblast attachment, mineralization and metabolic activity. ${ }^{10}$

The present study focused on the development of the HANP/PLGA/PVA composites by using the freeze-drying method. This study aimed to analyze the biodegradation properties and pore size of the HANP/PLGA/PVA composites. The findings of the study are expected to provide suggestions for synthetic bone grafts to avoid or recover bone loss following tooth extraction.

\section{Material and methods}

The following components were used: HANPs $\pm 60 \mathrm{~nm}$ (BATAN, Jakarta, Indonesia); PLGA 50:50 Mw 15,000-25,000 Da (PolySciTech, West Lafayette, USA); PVA fully hydrolized Mw 73,000 Da (Merck, Kenilworth, USA); phosphate-buffered saline (PBS) (Gibco ${ }^{\mathrm{TM}}$, Thermo Fisher Scientific, Waltham, USA); and ethyl acetate (Merck).

This study was conducted in May 2019. The study materials were divided into 4 groups: G1 (PVA alone); G2 (HANP/PVA); G3 (PLGA/PVA); and G4 (HANP/ PLGA/PVA). The HANP/PLGA/PVA composites contained 20\% (w/w) of HANP and 20\% (w/w) of PLGA. All of these composite specimens were prepared by means of the freeze-drying method at $-80^{\circ} \mathrm{C}$ for $24 \mathrm{~h}$.

The pore size analysis was determined by field emission scanning electron microscopy (FE-SEM) (FEI QuantaTM FEG 650; Thermo Fisher Scientific, Waltham, USA).

The biodegradation test was performed in triplicate $(n=3)$ by immersing the composites in $10 \mathrm{~mL}$ of the PBS solution ( $\mathrm{pH} 7.4$ ). They were then incubated at $37^{\circ} \mathrm{C}$ for 1, 3 and 6 weeks. All the composite specimens were weighed before immersing to determine their initial weight $\left(\mathrm{W}_{\mathrm{i}}\right)$. At the end of each degradation period, the swollen weight was measured immediately $\left(W_{s}\right)$. The composite specimens were then dried to determine the final dried weight $\left(\mathrm{W}_{\mathrm{f}}\right)$. Subsequently, the water uptake and water loss values were also determined. To calculate the water uptake value, equation 1 was used:

$$
\text { Water uptake }=\left[\frac{\mathrm{W}_{\mathrm{s}}-\mathrm{W}_{\mathrm{f}}}{\mathrm{W}_{\mathrm{f}}}\right] \times 100 \quad[\%]
$$

where:

$\mathrm{W}_{\mathrm{s}}$ - swollen weight [mg];

$\mathrm{W}_{\mathrm{f}}$ - final dried weight $[\mathrm{mg}]$.

Additionally, the water loss value was calculated with equation 2:

$$
\text { Water loss }=\left[\frac{\mathrm{W}_{\mathrm{i}}-\mathrm{W}_{\mathrm{f}}}{\mathrm{W}_{\mathrm{i}}}\right] \times 100 \quad[\%]
$$

where:

$\mathrm{W}_{\mathrm{i}}$ - initial weight [mg];

$\mathrm{W}_{\mathrm{f}}$ - final dried weight $[\mathrm{mg}]$.

Each measured sample contained 3 parallel test samples. Statistical analysis was performed using the one-way analysis of variance (ANOVA) (IBM SPSS Statistics for Windows, v. 25.0; IBM, Corp., Armonk, USA) and was considered statistically significant at $p<0.05$. 


\section{Results}

Figure 1 shows the FE-SEM images of the surface morphology and pore size of the composites. The representatives of the FE-SEM images show the natural distribution of the pore formation in the scaffold. Table 1 shows that the HANP/PLGA/PVA composites had the greatest pore size. Table 2 presents the initial weights, swollen weights and final dried weights of all composite specimens, which influenced the percentage of water uptake and water loss. Figure 2 shows the comparison of water uptake percentages for all composite specimens at different periods of time. The HANP/PLGA/PVA composites showed the highest water uptake percentage in the $3^{\text {rd }}$ and $6^{\text {th }}$ weeks $(730.46 \%$ and $731.07 \%$, respectively), indicating that water absorption was increased 7-fold as compared to the initial weight. Figure 3 shows that the HANP/PLGA/PVA composites exhibited a greater water loss value in the $6^{\text {th }}$ week $(67.69 \%)$ than other composites. With the absence of PLGA, the swelling ratio (water uptake percentage) of the HANP/PVA composites was half that of the HANP/PLGA/PVA composites, indicating that the incorporation of PLGA into the scaffold enhanced the biodegradation rate of the composites.
Table 1. Pore size of the composites $(n=3)$

\begin{tabular}{|lc|}
\multicolumn{1}{|c|}{ Composite } & Pore size $[\mu \mathrm{m}]$ \\
\hline PVA alone & $51.34 \pm 31.85$ \\
HANP/PVA & $54.53 \pm 35.74$ \\
\hline PLGA/PVA & $138.46 \pm 68.54^{*}$ \\
HANP/PLGA/PVA & $176.00 \pm 61.93^{*}$ \\
\hline
\end{tabular}

Data presented as mean $(M) \pm$ standard deviation $(S D)$.

* statistically significant differences in relation to all other groups $(p<0.05)$.

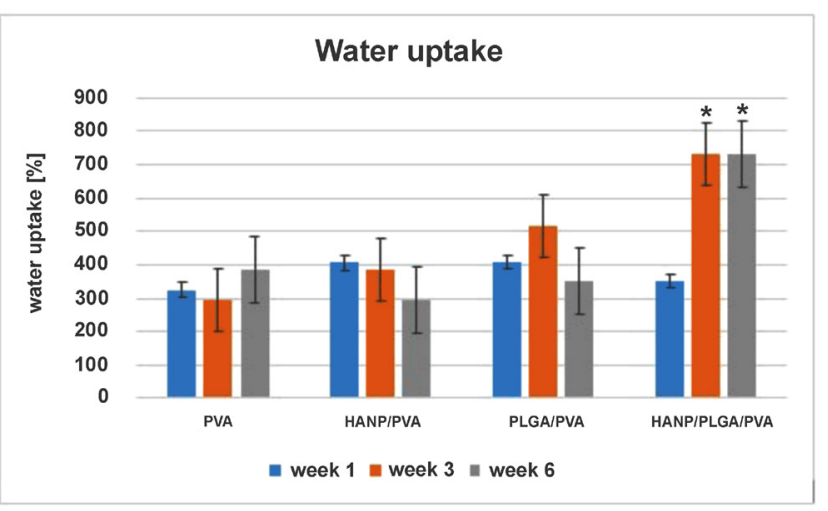

Fig. 2. Percentages of water uptake of the composites * $p<0.05$

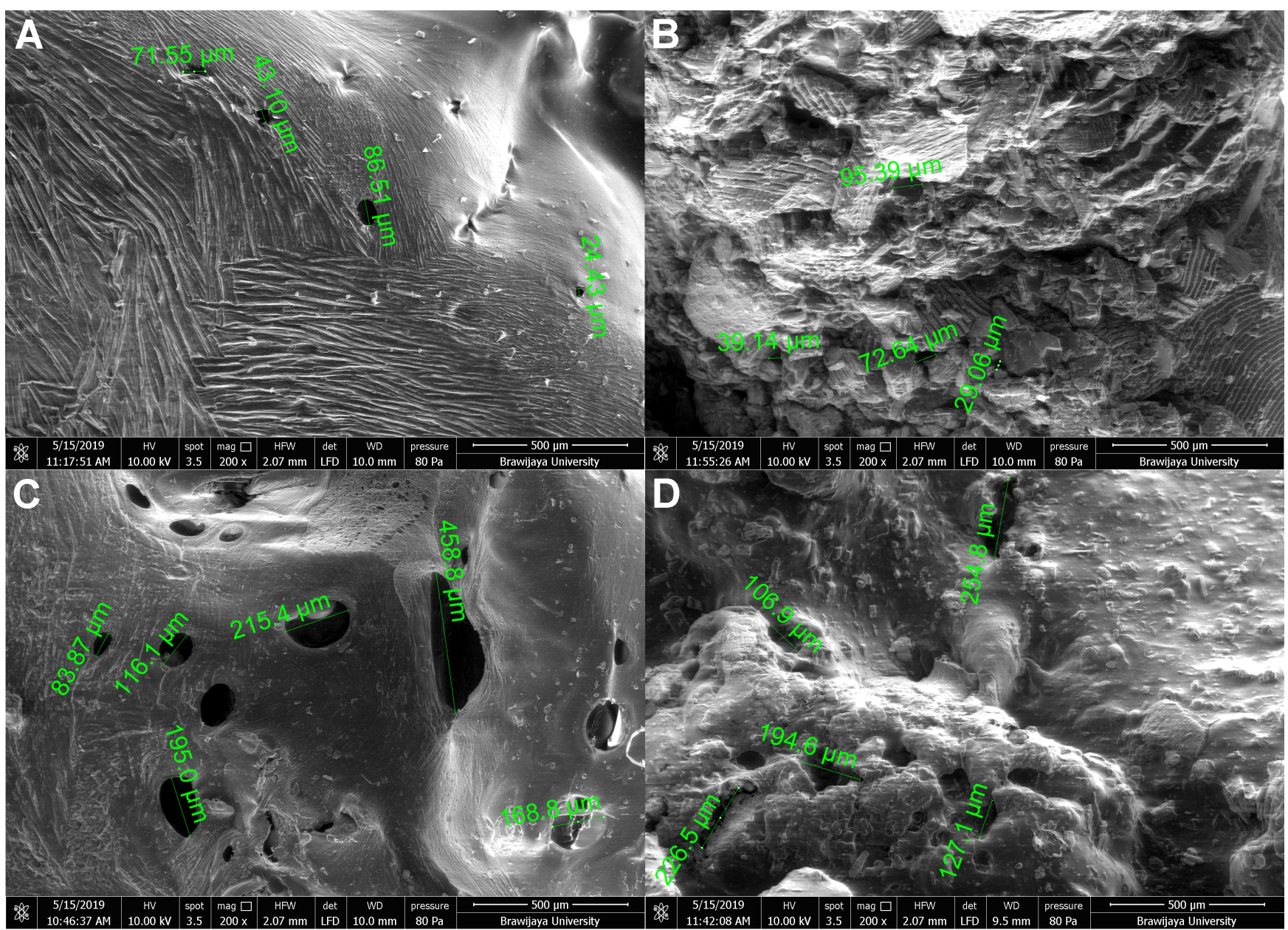

Fig. 1. Morphological analysis of the composites with field emission scanning electron microscopy (FE-SEM)

A - PVA alone; B - HANP/PVA; C - PLGA/PVA; D - HANP/PLGA/PVA.

PVA - polyvinyl alcohol; HANP - hydroxyapatite nanoparticle; PLGA - poly lactic-co-glycolic acid. 
Table 2. Weights of the composites $(n=3)$

\begin{tabular}{|c|c|c|c|c|c|c|c|}
\hline \multirow{2}{*}{ Composite } & \multirow{2}{*}{$\mathrm{W}_{\mathrm{i}}[\mathrm{mg}]$} & \multicolumn{2}{|c|}{ Week 1} & \multicolumn{2}{|c|}{ Week 3} & \multicolumn{2}{|c|}{ Week 6} \\
\hline & & $W_{\mathrm{s}}[\mathrm{mg}]$ & $W_{f}[\mathrm{mg}]$ & $W_{s}[\mathrm{mg}]$ & $W_{f}[\mathrm{mg}]$ & $\mathrm{W}_{\mathrm{s}}[\mathrm{mg}]$ & $W_{f}[m g]$ \\
\hline PVA alone & $340.00 \pm 12.29$ & $768.00 \pm 28.16$ & $180.33 \pm 15.70$ & $694.30 \pm 4.04$ & $175.33 \pm 13.58$ & $648.00 \pm 9.64$ & $121.00 \pm 11.79$ \\
\hline HANP/PVA & $401.30 \pm 64.53$ & $894.67 \pm 6.66$ & $177.00 \pm 4.00$ & $751.30 \pm 2.52$ & $154.67 \pm 9.07$ & $658.33 \pm 12.86$ & $167.33 \pm 10.07$ \\
\hline PLGA/PVA & $352.67 \pm 75.70$ & $913.00 \pm 7.55^{*}$ & $179.67 \pm 1.15$ & $904.67 \pm 5.86$ & $147.00 \pm 8.19$ & $759.00 \pm 10.58$ & $168.00 \pm 16.09$ \\
\hline HANP/PLGA/PVA & $348.67 \pm 49.89$ & $902.33 \pm 16.26$ & $200.33 \pm 18.77$ & $1,027.00 \pm 29.51^{*}$ & $123.67 \pm 14.19^{*}$ & $936.30 \pm 8.50^{*}$ & $154.67 \pm 11.59$ \\
\hline
\end{tabular}

Data presented as $M \pm S D$

$W_{i}$ - initial weight; $W_{s}-$ swollen weight; $W_{f}$ - final dried weight; ${ }^{*}$ statistically significant differences in relation to all other groups $(p<0.05)$.

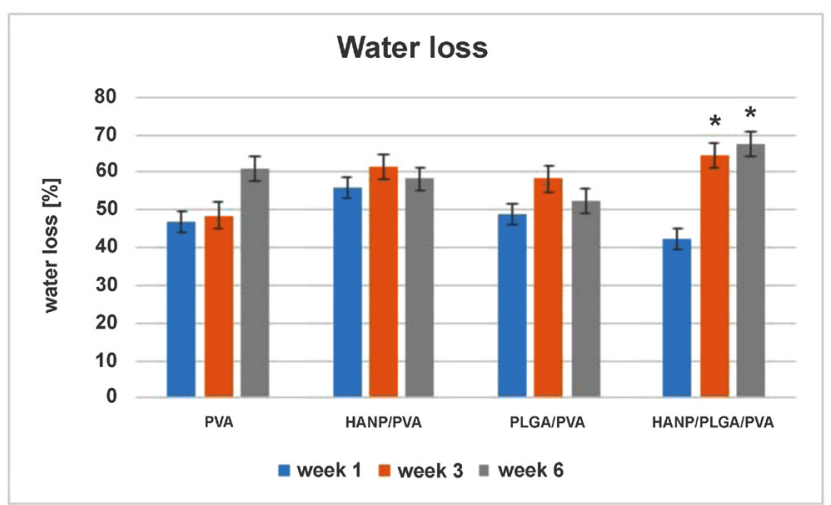

Fig. 3. Percentages of water loss of the composites

* $p<0.05$.

\section{Discussion}

Over the last decade, polymer and bioceramic composites have attracted much attention as biomaterials to be developed for bone regeneration. ${ }^{12,14,24,25}$ Figure 1 shows that the surface area of the HANP/PLGA/PVA composites was rougher than that of other composites, indicating that the addition of HANPs to the scaffold increases the surface area and its roughness. ${ }^{15}$ The surface roughness of composites influences their interaction with the biological environment. ${ }^{26,27}$ It also enhances cell adhesion, differentiation and proliferation. ${ }^{26-29}$ The pore size is mainly responsible for cell proliferation, migration and nutrition. ${ }^{15,16}$ Specific cells require different pore sizes for optimal attachment and proliferation. ${ }^{26}$ Research by Chang and Wang showed that osteoblast migration was faster through scaffolds with a pore size larger than $100 \mu \mathrm{m} .{ }^{26}$ A study by Loh and Choong demonstrated that the optimal pore size of a scaffold to enhance cell migration and proliferation ranged from $100 \mu \mathrm{m}$ to $350 \mu \mathrm{m} .{ }^{15}$ An interconnected network serves the improvement in the mechanical stability of the implant through the incorporation of PLGA. ${ }^{30}$ Moreover, the selection of the technique to prepare the composite scaffold for bone regeneration has a great impact on the pore size and porosity of the scaffold. ${ }^{15,16,31,32}$ Freeze drying is a conventional technique that allows frozen water to sublimate directly and results in pore formation. ${ }^{15,31,32}$ The pore size of the composite depends on the ratio of water to the polymer solution, the freezing temperature and the viscosity of the emulsion. ${ }^{15}$ The pore size also affects the expression of gene markers and the secretion of glycosaminoglycan (GAG) ${ }^{15}$ Biodegradable materials are ideal biomaterials in oral and maxillofacial surgery and in orthopedics, since they do not require a second surgical event for removal. ${ }^{4,13,18}$ In that vein, non-biodegradable composites have some significant drawbacks, including an increase in hospitalization time, in healthcare cost and in the risk of infection. ${ }^{33}$

\section{Conclusions}

The presence of HANPs in the composites could affect the surface roughness and increase the surface area. The incorporation of PLGA into the scaffold could increase the pore size and biodegradation rate of the composites as compared to those of PVA alone or HANP/PVA. The HANP/PLGA/PVA composites demonstrated optimal pore size, morphology and degradability, which indicates their high potential as an effective bone scaffold to repair the alveolar defect following tooth extraction or for alveolar preservation.

\section{ORCID iDs}

Feni Istikharoh (1) https://orcid.org/0000-0003-2816-1036 Hidayat Sujuti (1) https://orcid.org/0000-0003-2542-8575

Edi Mustamsir (1) https://orcid.org/0000-0002-8914-6166 Astika Swastirani (1) https://orcid.org/0000-0003-3300-7631

\section{References}

1. Fithri Z, Rochim A, Cholid Z. Distribution of tooth extraction based on sociodemographic characteristic of Dental Hospital of University of Jember patients in January-December 2014 [in Indonesian]. e-J Pustaka Kesehatan. 2017;5(1):177-184.

2. Hansson S, Halldin A. Alveolar ridge resorption after tooth extraction: A consequence of a fundamental principle of bone physiology. J Dent Biomech. 2012;3:1758736012456543. doi:10.1177/1758736012456543

3. Mahyudin F, Utomo DN, Suroto H, Martanto TW, Edward M, Gaol IL. Comparative effectiveness of bone grafting using xenograft freeze-dried cortical bovine, allograft freeze-dried cortical New Zealand white rabbit, xenograft hydroxyapatite bovine, and xenograft demineralized bone matrix bovine in bone defect of femoral diaphysis of white rabbit: Experimental study in vivo. Int J Biomater. 2017;2017:7571523. doi:10.1155/2017/7571523

4. Sheikh Z, Najeeb S, Khurshid Z, Verma V, Rashid H, Glogauer M. Biodegradable materials for bone repair and tissue engineering applications. Materials (Basel). 2015;8(9):5744-5794. doi:10.3390/ma8095273 
5. Tian Q, Lin J, Rivera-Castaneda L, et al. Nano-to-submicron hydroxyapatite coatings for magnesium-based bioresorbable implants - deposition, characterization, degradation, mechanical properties, and cytocompatibility. Sci Rep. 2019;9:810. doi:10.1038/s41598-018-37123-3

6. Barretto Montandon AA, Zuza EP, Corrêa de Toledo BE. Prevalence and reasons for tooth loss in a sample from a dental clinic in Brazil. Int J Dent. 2012;2012:ID 719750. doi:10.1155/2012/719750

7. Taşsöker $M$, Menziletoğlu D, Baştürk F, Karabekiroğlu S, Şener $S$. Investigation of tooth extraction reasons in patients who applied to a dental faculty. Meandros Med Dent J. 2018;19:219-225. doi: $10.4274 /$ meandros.40085

8. Hong CE, Lee JY, Choi J, Joo JY. Prediction of the alveolar bone level after the extraction of maxillary anterior teeth with severe periodontitis. JPeriodont Implant Sci.2015;45(6):216-222. doi:10.5051/jpis.2015.45.6.216

9. Moreno AR, Magdaleno MO, Islas MM, et al. Postextraction alveolar preservation and use of the crown of the extracted tooth as a temporary restoration. Case Rep Dent. 2019;2019:4262067. doi:10.1155/2019/4262067

10. Hämmerle CHF, Tarnow D. The etiology of hard- and soft-tissue deficiencies at dental implants: A narrative review. J Clin Periodontol. 2017;45(Suppl 20):S267-S277. doi:10.1111/jcpe.12955

11. Avila-Ortiz G, Elangovan S, Kramer KWO, Blanchette D, Dawson DV. Effect of alveolar ridge preservation after tooth extraction: A systematic review and meta-analysis. J Dent Res. 2014;93(10):950-958. doi:10.1177/0022034514541127

12. Miyazaki T, Ishikawa K, Shirosaki Y, Ohtsuki C. Organic-inorganic composites designed for biomedical applications. Biol Pharm Bull. 2013;36(11):1670-1675. doi:10.1248/bpb.b13-00424

13. Daud NM, Sing NB, Yusop AH, Abdul Majid FA, Hermawan H. Degradation and in vitro cell-material interaction studies on hydroxyapatite-coated biodegradable porous iron for hard tissue scaffolds. J Orthop Transl. 2014;2(4):177-184. doi:10.1016/j.jot.2014.07.001

14. Kattimani VS, Kondaka S, Lingamaneni KP. Hydroxyapatite - past, present, and future in bone regeneration. Bone Tissue Regener Insights. 2016;7:8-19. doi:10.4137/btri.s36138

15. Loh QL, Choong C. Three-dimensional scaffolds for tissue engineering applications: Role of porosity and pore size. Tissue Eng Part B Rev. 2013;19(6):485-502. doi:10.1089/ten.TEB.2012.0437

16. Wang $Q$, Wang $Q$, Wan $C$. The effect of porosity on the structure and properties of calcium polyphosphate bioceramics. Ceramics Silikaty. 2011;55(1):43-48. https://www.irsm.cas.cz/materialy/cs_content/2011/Wang_CS_2011_0000.pdf. Accessed August 1, 2019.

17. Ryan AJ, Gleeson JP, Matsiko A, Thompson EM, O'Brien FJ. Effect of different hydroxyapatite incorporation methods on the structural and biological properties of porous collagen scaffolds for bone repair. J Anat. 2015;227(6):732-745. doi:10.1111/joa.12262

18. Ortega-Oller I, Padial-Molina M, Galindo-Moreno P, O'Valle F, JódarReyes $A B$, Peula-García JM. Bone regeneration from PLGA micronanoparticles.BiomedRes/nt.2015;2015:415289.doi:10.1155/2015/415289

19. Ma'ruf T, Siswomihardjo W, Soesatyo MHNE, Tontowi AE. Polyvinyl alcohol-hydroxyapatite composite reinforced with catgut fibers as biodegradable bone plates. 3rd International Conference on Instrumentation, Communications, Information Technology, and Biomedical Engineering (ICICI-BME). 2013:246-248. doi:10.1109/ICICI-BME.2013.6698501

20. Tontowi AE, Perkasa DP, Siswomihardjo W, Darwis D. Effect of polyvinyl alcohol (PVA) blending and gamma irradiation on compressive strength of FHAp/FGel composite as candidate of scaffold. Int J Eng Technol. 2016;8(1):108-116. https://www.enggjournals. com/ijet/docs/IJET16-08-01-007.pdf. Accessed August 1, 2019.

21. Kapoor DN, Bhatia A, Kaur R, Sharma R, Kaur G, Dhawan S. PLGA: A unique polymer for drug delivery. Ther Deliv. 2015;6(1):41-58. doi:10.4155/tde.14.91

22. Shibata A, Yada S, Terakawa M. Biodegradability of poly(lacticco-glycolic acid) after femtosecond laser irradiation. Sci Rep. 2016;6:27884. doi:10.1038/srep27884

23. Makadia HK, Siegel SJ. Poly lactic-co-glycolic acid (PLGA) as biodegradable controlled drug delivery carrier. Polymers (Basel). 2011;3(3):1377-1397. doi:10.3390/polym3031377

24. Costa-Pinto AR, Martins AM, Castelhano-Carlos MJ, et al. In vitro degradation and in vivo biocompatibility of chitosanpoly(butylene succinate) fiber mesh scaffolds. J Bioact Compat Polym. 2014;29(2):137-151. doi:10.1177/0883911514521919
25. Istikharoh F, Sujuti H, Mustamsir E, Swastirani A, Milla LE. Poly(lacticco-glycolic acid) enhance of biodegradability properties and pore size of hydroxyapatite nanoparticle/PVA composites for alveolar ridge preservation. Malaysian J Med Health Sci. 2019;15(Supp 7):63.

26. Chang HI, Wang Y. Responses to surface and architecture of tissue engineering scaffolds. Regenerative Medicine and Tissue Engineering - Cells and Biomaterials. London, UK: IntechOpen Ltd.; 2011:569-589. doi:10.5772/837

27. Zamani F, Amani-Tehran M, Latifi M, Shokrgozar MA. The influence of surface nanoroughness of electrospun PLGA nanofibrous scaffold on nerve cell adhesion and proliferation. J Mater Sci Mater Med. 2013;24(6):1551-1560. doi:10.1007/s10856-013-4905-6

28. Li L, Crosby K, Sawicki M, Shaw LL, Wang Y. Effects of surface roughness of hydroxyapatite on cell attachment and proliferation. J Biotechnol Biomater. 2012;2:150. doi:10.4172/2155-952X.1000150

29. Bobbert FSL, Zadpoor AA. Effects of bone substitute architecture and surface properties on cell response, angiogenesis, and structure of new bone. J Mater Chem B. 2017;5(31):6175-6193. doi:10.1039/c7tb00741h

30. Garg T, Singh O, Arora S, Murthy R. Scaffold: A novel carrier for cell and drug delivery. Crit Rev Ther Drug Carrier Syst. 2012;29(1):1-63. doi:10.1615/critrevtherdrugcarriersyst.v29.i1.10

31. Arsiccio A, Sparavigna AC, Pisano R, Barresi AA. Measuring and predicting pore size distribution of freeze-dried solutions. Dry Technol. 2019;37(4):435-447. doi:10.1080/07373937.2018.1430042

32. Assegehegn G, Brito-de la Fuente E, Franco JM, Gallegos C. The importance of understanding the freezing step and its impact on freezedrying process performance. J Pharm Sci. 2019:108(4):1378-1395. doi:10.1016/j.xphs.2018.11.039

33. Iqbal N, Khan AS, Asif A, Yar M, Haycock JW, Rehman IU. Recent concepts in biodegradable polymers for tissue engineering paradigms: A critical review. Int Mater Rev. 2019;64(2):91-126. doi:10.108 0/09506608.2018.1460943 